\title{
Is Health Care Support Associated with Better Educational Achievement in Sensorineural Hearing Impaired Students with Overlooked Recurrent Otitis Media?
}

\author{
Naeimeh Daneshmandan, ${ }^{1}$ Farin Soleimani, ${ }^{1}$ Nadia Azari, ${ }^{1}$ Pouya Mahmoudzadeh Tussi, ${ }^{2}$ and Poopak \\ Izadi $^{3, *}$ \\ ${ }^{1}$ Pediatric Neurorehabilitation Research Center, University of Social Welfare and Rehabilitation Sciences, Tehran, IR Iran \\ ${ }^{2}$ Medical Sciences Research Center, Shahid Beheshti University of Medical Sciences, Tehran, IR Iran \\ ${ }^{3}$ Department of Otolaryngology, School of Medicine, Shahed University, Tehran, IR Iran \\ "Corresponding author: Dr. Poopak Izadi, Department of Otolaryngology, Shahid Mostafa Khomeini Hospital, Shahed University, Keshavarz Blvd, Italia Ave, Tehran 1466947893, \\ IR Iran. Tel: +98-2188969437, Fax: +98-2188969437, E-mail: popakizadi@yahoo.com
}

Received 2016 November 08; Accepted 2017 January 10.

\begin{abstract}
Background: Otitis media is an important health care problem in school-age children. Moreover, the prevalence of allergic rhinitis, a major and common cause of otitis media, is increasing among children. Recurrent otitis media may occur without any noticeable symptoms and affect the auditory threshold (AT). Only a few decibles increase in hearing loss does not have the same effect on the hearing ability of individuals with different degrees of hearing loss. With this background in mind, in this study, we aimed to determine whether diagnosis and medical treatment of overlooked recurrent otitis media are associated with the educational achievement of students with sensorineural hearing impairment.

Methods: The present study with a pretest-posttest design was conducted on 30 students (aged 12 - 20 years) with bilateral sensorineural hearing impairment, AT above $30 \mathrm{~dB}$ HL in the better ear, and recurrent (2 episodes) middle ear infection over 9 months during 2012 - 2014. The participants were examined regularly and received medical treatment when indicated. The mean scores of total average, Persian literature (eg, reading, writing, and spelling), and mathematics were measured to assess the subjects' educational achievement.

Results: Based on the findings, the total average scores significantly changed from 16.2 to 17.2. Also, the students' Persian literature (from 16.8 to 18 ) and mathematics (from 13.8 to 16.7) scores were significantly improved. In addition, AT considerably decreased after the medical intervention (from $73 \pm 14.7$ to $56.3 \pm 13.8 \mathrm{~dB} \mathrm{HL}$ ).

Conclusions: It seems that detection and treatment of overlooked middle ear infection in hearing impaired students, as part of comprehensive health care services, can improve their AT, diminish their hearing disabilities, and ameliorate their educational difficulties; consequently, provision of health care services is associated with better educational achievement.
\end{abstract}

Keywords: Otitis Media, Auditory Threshold, Educational Achievements, Sensorineural Hearing Loss, Comprehensive Health Care

\section{Background}

Hearing loss in school-age children is one of the major public health problems in developing countries (1). Two-thirds of hearing impaired patients live in developing countries, while around $50 \%$ of these cases can be prevented (2). According to the Classification of functioning, disability, and health by the world health organization (WHO), disabling hearing impairment is defined as permanent hearing loss with an auditory threshold (AT) above 30 $\mathrm{dB}$ in children under 15 years and AT above $40 \mathrm{~dB}$ in adults at frequencies of $0.5,1,2$, and $4 \mathrm{kHz}$ (3).

It is well recognized that hearing loss affects speech and language development, thereby leading to learning problems and poor academic achievement among children (4-6). Literacy development of hearing impaired chil- dren (HIC) is a major issue, influenced by various disciplines. Health, education, and social welfare sectors play pivotal roles in this area through secondary (early detection) and tertiary (timely interventions via integrated rehabilitation services) prevention (7). Moreover, individualized factors, such as severity of sensorineural hearing loss (the most important factor) and family support, considerably influence the patient's prognosis and differentiate HIC from their peers (8).

Another important health care problem in school-age children is otitis media (9). This type of infection is defined as "an inflamation of the middle ear without refrence to etiology or pathogenesis". Otitis media without effusion is a stage of middle ear inflamation in which "the mucosa of the middle ear is involved, but no effusion is present" (10). 
On the other hand, allergic diseases such as allergic rhinitis are very common in children and show an increasing prevalence $(11,12)$. In fact, allergic rhinitis, an important etiological cause of otitis media in childhood, is known to aggravate the Eustachian tube dysfunction (13).

Otitis media in children affects different developmental domains and has been discussed from different viewpoints, including otology, pediatrics, speech, language, and educational/psychological aspects of growth in children (14). Otitis media (with or without effusion) with negative pressure in the middle ear is associated with additional conductive hearing loss (15). Considering the fact that hearing loss does not develop in a linear fashion, each $10 \mathrm{~dB}$ increase in hearing loss does not have the same effect on the hearing ability of individuals with normal hearing function or two different people with different degrees of hearing loss (15).

Speech perception, along with favorable speech conception (or speech and auditory skills), directly influences the reading comprehension skills and learning abilities of HIC (16). On the other hand, since children with severe hearing loss are not sensitive to changes in their hearing threshold, ear diseases may be easily overlooked. Therefore, few cases of conductive hearing loss, concomitant with severe to profound sensorineural hearing loss, have been reported in the medical literature (17).

Early detection and interventional treatment of hearing loss in newborns have been successful in Iran, and $80 \%$ of hearing impaired students attend regular schools (18); however, lack of a tracking system makes us alert about their educational achievement. In fact, the number of school-age children with hearing loss has been documented, whereas the percentage of graduated students and their graduation level are yet to be addressed.

Identification of the effect of overlooked ear diseases, specifically middle ear problems (influencing the hearing potential), on the educational achievement of HIC can help us determine the pitfalls and establish the role of public health care services in ameliorating the educational difficulties of these children; in addition, it may help raise the quality of life among HIC. With this background in mind, in this study, we aimed to determine whether free regular ear, nose, and throat (ENT) examination and medical treatment of otitis media (through usual medical procedures and treatments) are associated with the academic achievement of hearing impaired students in regular educational settings.

\section{Methods}

\subsection{Participants}

The present study with a pretest-posttest design was conducted on 30 bilateral sensorineural hearing impaired students (SNHIS) with recurrent otitis media, selected from 14 schools, using the following sample size formula $(\alpha=5 \%, \beta=20 \%)$ :

$n=\frac{\left(z_{1-\frac{\alpha}{2}}+z_{1-\beta}\right)^{2} \sigma_{\delta}^{2}}{\delta^{2}}+\frac{z_{1-\frac{\alpha}{2}}^{2}}{2}$

The subjects were selected from a primary sample of 466 SNHIS with a low socioeconomic status. All the participants were registered in the deaf welfare clinic, affiliated to the welfare organization. The subjects were examined during the fall, winter, and spring of 2012 - 2014.

Among 200 students, who were examined in one session, 34 cases showed otitis media. A total of 266 students were checked 3 times during 3 seasons, among whom 80 cases showed signs of otitis media in 3 seasons. Since one of the inclusion criteria in this study was 2 episodes of infection during 3 seasons, 15 subjects were excluded from the study after evaluation, as only one episode of infection was detected during 3 seasons of evaluation. Therefore, 65 children were included in the study (23 cases were recorded to have type B tympanograms, and the rest were identified with type $C$ tympanograms; negative pressure $\geq 300 \mathrm{~mm}$ $\mathrm{H}_{2} \mathrm{O}$ ).

Another inclusion criterion was use of two hearing aids during the study. Among 65 eligible students, 14 experienced hearing aid failure, which could be a confounding factor for their academic achievement; as a result, they were excluded from the study. Among the remaining 51 students, 21 cases were also eliminated, as they did not meet the third inclusion criterion (ie, bilateral otitis media) and had unilateral infections.

A total of 30 children were recruited in the study, based on the following inclusion criteria: (1) bilateral sensorineural hearing loss with an auditory threshold (AT) of $>30$ $\mathrm{dB}$ HL in the better ear; (2) bilateral otitis media with or without effusion (or middle ears with negative pressure $\geq$ $300 \mathrm{~mm} \mathrm{H}_{2} \mathrm{O}$ ) and 2 sessions of medical intervention per 9 months; (3) use of appropriate hearing aids in both ears; (4) similar educational settings such as regular schools; (5) Normal IQ; (6) no other disabilities; and (7) cooperation and participation in long-term monitoring of middle ear function and recording of educational performance.

Finally, 28 students remained in the study; however, 2 subjects quit school and were excluded from the research. The present study was carried out at Asma research and educational rehabilitation clinic and continued until October 2014. 


\subsection{Procedures}

AT was evaluated via pure tone audiometry (PTA) at frequencies of $250,500,1000,2000$, and $4000 \mathrm{~Hz}$. The auditory threshold shift (ATS) in the better ear was assessed, based on speech reception threshold (SRT) changes at 500, 1000, and $2000 \mathrm{~Hz}$. Both PTA and SRT were determined by AD229 Audiometer (Interacoustics, Denmark). Also, the middle ears were assessed by otoscopy (Welch Allyn Model 22820) and screened objectively using impedance audiometry (Madsen AZ7, Denmark), also known as tympanometry.

The type of tympanograms was recorded as follows: type $\mathrm{A}$ (normal middle ear function), type $\mathrm{B}$ (with effusion), and type $\mathrm{C}$ (negative middle ear pressure and high negative pressure $\geq 300 \mathrm{mmH}_{2} \mathrm{O}$ ). Medical interventions, such as wax removal, medical treatment of middle ear infection (mainly through prescription of antibiotics, eg, $8 \mathrm{mg} / \mathrm{kg}$ of cefixime or co-amoxiclav), and control of allergic rhinitis (mostly through topical corticosteroids, eg, $50 \mathrm{mcg}$ of fluticasone propionate twice per day), were provided for each patient by the otolaryngologist when indicated.

All children received up to 2 years of free medical service through regular ENT examinations every 1 to 2 months. AT and ATS were expressed as $\mathrm{dB}$ HL before and after the medical intervention. During the intervention, in case of abnormal tympanogram (such as high negative middle ear pressure $\geq 300 \mathrm{mmH}_{2} \mathrm{O}$ ) or type B tympanogram due to middle ear infection, the subject was carefully followed-up by the otolaryngologist and audiologist every week.

Tympanometry was carried out weekly during $3-6$ weeks. When the tympanogram returned to type A after the medical intervention, PTA and SRT were recorded. Any changes in SRT before/after the medical intervention were compared and reported as additional conductive hearing loss or ATS (in dB HL). The primary outcome was the mean total average score (the average score of all study subjects during a school year), the secondary outcomes were the scores of mathematics and Persian literature (average scores of reading, writing, and spelling), and the tertiary outcome was the mean ATS.

The mean scores of mathematics and Persian literature were investigated and used to assess the students' educational achievement before and after the medical intervention during 2013 - 2014. In this study, the Iranian grading system (marks from 0 to 20 ) was employed to measure the educational achievement.

The ethics committee of the University of Social Welfare and Rehabilitation Sciences approved the present study (No., USWR.REC.1392.112). Also, informed consent forms were obtained from the parents.

\subsection{Statistical Analysis}

Continuous data are expressed as mean \pm SD and analyzed using SPSS version 21. Non-parametric Wilcoxon test was used to determine the difference in the average of two dependent samples (before and after the intervention). Fisher's exact test was performed for determining the association between qualitative variables. Also, MannWhitney test was used to investigate the difference in educational performance between different age groups and subjects with different degrees of hearing loss. P value less than 0.05 was considered statistically significant.

\section{Results}

In the primary sample of 466 SNHIS, 200 were examined during one season, and 34 (17\%) cases of middle ear problems were detected. In total, 266 students were examined 3 times during 3 seasons, among whom 80 (30\%) cases had otitis media and 65 cases had middle ear infection with or without effusion ( 2 episodes during 9 months); therefore, they were included in the study. Nevertheless, 15 cases were eliminated from the study due to only one episode of infection during 3 seasons. Also, 14 children used one hearing aid and were consequently eliminated from the study. Among 51 children with middle ear infection and two hearing aids, 21 cases were excluded due to unilateral otitis media. Hence, 30 children with bilateral otitis media and AT above $30 \mathrm{~dB}$ HL in the better ear were selected; however, 2 cases quit school and were excluded from the analysis.

Ultimately, the study sample consisted of 28 SNHIS with the mean age of $15.5 \pm 2.2$ years (range: 12 - 20 years). In total, 15 children were 12 to 15 years old, while 13 cases were within the age range of 16 - 20 years. The study sample included 16 boys and 12 girls, attending educational settings similar to a regular school. The final visit by the otolaryngologist was in the past 6 - 12 months in 4 children. Also, in 12,8 , and 4 children, the final visit was within the past 1 - 2 years, 2 - 3 years, and $\geq 3$ years, respectively. Most of the participants ( 24 cases) were visited by the otolaryngologist for more than a year, while only 4 (15\%) children were examined for less than a year.

The degree of hearing loss in the subjects was as follows: 31 - $50 \mathrm{~dB}$ in 13 (46.4\%) children, 51 - $70 \mathrm{~dB}$ in 13 (46.4\%) children, and 71 - $90 \mathrm{~dB}$ in $2(7 \%)$ children. AT was less than $50 \mathrm{~dB}$ HL in 13 children and over $50 \mathrm{~dB}$ HL in 15 (54\%) students. The mean AT was $73 \pm 14.7$ (min: $40 \mathrm{~dB}$ HL, max: $90 \mathrm{~dB} \mathrm{HL}$ ) in the better ear before the medical intervention. The frequency of otitis media during 9 months was 2 episodes in 21 (75\%) children, 3 episodes in 3 (10.7\%) children, and more than 3 episodes in 4 (14.3\%) cases. The participants' demographics are reported in Table 1. 
Table 1. Demographic Characteristics of the Participants

\begin{tabular}{|c|c|c|}
\hline Characteristics & & Values $^{\mathrm{a}}$ \\
\hline \multirow{2}{*}{ Sex } & Male & $16(57)$ \\
\hline & Female & $12(43)$ \\
\hline \multirow{3}{*}{ Age, $y$} & $12-20$ & $28(100)$ \\
\hline & $12-15$ & $15(54)$ \\
\hline & $16-20$ & $13(46)$ \\
\hline \multirow{3}{*}{$\begin{array}{l}\text { Hearing threshold in the better ear, } \\
\text { dB }\end{array}$} & $<50(31-50)$ & $13(46)$ \\
\hline & $>50(51-70)$ & $13(46)$ \\
\hline & $71-90$ & $2(7)$ \\
\hline $\begin{array}{l}\text { SRT status before the intervention,dB } \\
\text { HL }\end{array}$ & Min: 40, Max: 90 & $73 \pm 14.7$ \\
\hline \multirow{3}{*}{$\begin{array}{l}\text { Frequency of otitis media during } 6 \\
\text { months, episodes }\end{array}$} & 2 & $21(75)$ \\
\hline & 3 & $3(10.7)$ \\
\hline & $>3$ & $4(14.3)$ \\
\hline \multirow{2}{*}{ The final visit } & In less than a year & $4(15)$ \\
\hline & In more than a year & $24(85)$ \\
\hline
\end{tabular}

${ }^{\mathrm{a}}$ Values are expressed as mean \pm SD or No. (\%).

\subsection{The Effect of Medical Intervention on the Average Marks}

The average marks significantly improved in the study sample and changed from 16.2 to 17.2 $(\mathrm{P}<0.0001)$. General progress was observed, which seems to be associated with the provision of free and regular health care support (Table 2).

\subsection{The Effect of Medical Intervention on the Students' Marks}

Based on the findings, the students' Persian literature marks were improved; the mean scores significantly increased from 16.8 to $18(\mathrm{P}=0.004)$. Also, math scores significantly increased, with a greater improvement, compared to Persian literature $(\mathrm{P}<0.0001)$. The mean scores changed from 13.8 before the medical intervention to 16.7 after the intervention (Table 2). Progress was observed in the students' marks, which seems to be associated with the provision of free and regular health care support (Table 2).

\subsection{The Effect of Medical Intervention on AT Improvement}

AT significantly improved after the medical intervention. On the other hand, SRT significantly decreased from $73 \pm 14.7$ to $56.3 \pm 13.8 \mathrm{~dB}$ HL after the medical intervention $(\mathrm{P}<0.0001$; Table 2).

3.4. The Relationship Between Age and Educational Performance

We also compared the marks between the two age groups (12 - 15 and 16 - 20 years old). We found that the scores before and after the intervention did not differ between the two age groups (Mann-Whitney test; Table 3).

\subsection{The Relationship Between Different Degrees of Hearing Loss and Educational Performance}

The scores were compared between two groups with different degrees of hearing loss ( $30-50 \mathrm{~dB}$ and $50-90 \mathrm{~dB}$ ). The results showed that the scores before and after the intervention were not significantly different (Mann-Whitney test; Table 4).

\section{Discussion}

The present study aimed to assess the association between health care support (concerning the detection and treatment of overlooked recurrent otitis media) and academic achievement among SNHIS through regular otologic examination. We hypothesized that most episodes of otitis media remain disregarded due to unnoticeable minor signs and symptoms. Besides, loudness growth is nonlinear and the undetected increase in hearing loss (specifically at a hearing threshold above $30 \mathrm{~dB}$ ) may majorly affect the hearing ability and learning process of SNHIS.

In the present study, we found a positive association between health care support) through regular ENT examination and medical intervention) and better educational achievement in the study sample. We can explain this finding in three parts:

Part 1: The increase in the total average marks after the medical intervention showed an improvement in the educational performance of students, most probably due to the treatment of mild conductive hearing loss through medical intervention. The current results were consistent with studies by Bess et al. (19)in 1998 and Khairi Md Daud et al. in 2010 (20), which highlighted the effect of even mild hearing loss on reduced educational performance of hearing impaired school-age children in comparison to their peers with a normal hearing function.

In the present study, we compared educational achievement in two different age groups (age range: 12 - 15 and 16 - 20 years), as well as two groups with different degrees of hearing loss (30 - 50 and $50-90 \mathrm{~dB}$ ). The findings revealed that the marks were not significantly different between these groups; therefore, medical intervention could actually improve educational performance.

Otitis media affects the educational achievement of children in two ways. First, recurrent early childhood otitis media induces auditory processing deficits and considerably delays speech and language development, which is followed by reading disorders and learning problems (21, 22). Second, the increase in hearing loss, which was mentioned before and was the main interest of the present 
Table 2. Comparison of the Average Variables Before and After the Intervention

\begin{tabular}{|c|c|c|c|c|}
\hline Variables & Mean \pm SD & Median & Min-Max & PValue \\
\hline SRT & & & & $<0.0001$ \\
\hline Before & $73 \pm 14.7$ & 80 & $40-90$ & \\
\hline After & $56.3 \pm 13.8$ & 57.5 & $30-80$ & \\
\hline Literature scores & & & & 0.004 \\
\hline Before & $16.8 \pm 2.7$ & 17 & $8-20$ & \\
\hline After & $18 \pm 2$ & 19 & $10-20$ & \\
\hline Math scores & & & & $<0.0001$ \\
\hline Before & $13.8 \pm 3.9$ & 14.4 & 7-19 & \\
\hline After & $16.7 \pm 2.5$ & 16.9 & $12-20$ & \\
\hline Total average & & & & $<0.0001$ \\
\hline Before & $16.2 \pm 1.9$ & 16.6 & $12.5-19.1$ & \\
\hline After & $17.2 \pm 1.9$ & 17.4 & $13.4-19.5$ & \\
\hline
\end{tabular}

Table 3. Comparison of the Scores Between Two Age Groups ${ }^{\mathrm{a}}$

\begin{tabular}{|c|c|c|c|}
\hline \multirow[t]{2}{*}{ Scores } & \multicolumn{2}{|c|}{ Age Groups, y } & \multirow[t]{2}{*}{ P Value } \\
\hline & $12-15(n=15)$ & $16-20(n=13)$ & \\
\hline \multicolumn{4}{|l|}{ Literature } \\
\hline Before & $17.47 \pm 1.96$ & $16.06 \pm 3.26$ & 0.254 \\
\hline After & $18.47 \pm 1.06$ & $17.42 \pm 2.72$ & 0.555 \\
\hline \multicolumn{4}{|l|}{ Mathematics } \\
\hline Before & $13.20 \pm 4.09$ & $14.58 \pm 3.66$ & 0.636 \\
\hline After & $16.67 \pm 2.82$ & $16.79 \pm 2.23$ & 0.928 \\
\hline \multicolumn{4}{|l|}{ Total average } \\
\hline Before & $16.58 \pm 2.17$ & $15.86 \pm 1.61$ & 0.294 \\
\hline After & $17.42 \pm 1.98$ & $16.85 \pm 1.77$ & 0.316 \\
\hline
\end{tabular}

${ }^{\mathrm{a}}$ The Mann-Whitney test shows that the scores (before and after the intervention) are not significantly different between the two age groups (12 - 15 and 16 20 years).

study, is effective, as well. In the past, hearing impaired students attended special schools, whereas today, their presence in mainstream schools is highly advocated $(23,24)$. Therefore, these students should cope with their normal peers through residual hearing. This competition can be difficult for these students, and they need to be supported through eliminating the risk factors and enhancing their capabilities or assets.

Part B: In the present study, we also explored the students' educational achievement by assessing their average math scores with respect to improved residual hearing. The subjects showed better performance in mathematics, and the mean scores raised by 2.9 marks.
Table 4. Comparison of the Scores Between Two Groups with Different Degrees of Hearing Loss ${ }^{\mathrm{a}}$

\begin{tabular}{|c|c|c|c|}
\hline \multirow[t]{2}{*}{ Scores } & \multicolumn{2}{|c|}{ Threshold Level Groups, db } & \multirow[t]{2}{*}{ PValue } \\
\hline & $30-50(n=13)$ & $50-90(n=15)$ & \\
\hline \multicolumn{4}{|c|}{ Literature scores } \\
\hline Before & $16.38 \pm 3.33$ & $17.18 \pm 2.03$ & 0.650 \\
\hline After & $17.38 \pm 2.63$ & $18.50 \pm 1.21$ & 0.294 \\
\hline \multicolumn{4}{|l|}{ Math scores } \\
\hline Before & $13.69 \pm 3.95$ & $13.97 \pm 3.97$ & 0.751 \\
\hline After & $16.65 \pm 2.49$ & $16.78 \pm 2.62$ & 0.786 \\
\hline \multicolumn{4}{|l|}{ Total average } \\
\hline Before & $15.83 \pm 2.29$ & $16.61 \pm 1.55$ & 0.363 \\
\hline After & $16.90 \pm 2.06$ & $1.38 \pm 1.74$ & 0.555 \\
\hline
\end{tabular}

${ }^{\mathrm{a}}$ The Mann-Whitney test shows that the scores (before and after the intervention) are not significantly different between the two threshold level groups (30 -50 and $50-90 \mathrm{db}$ ).

Part C: we found that the mean scores of Persian literature improved by 1.2 marks; the mean scores of mathematics were higher than literature scores. These results were consistent with the findings reported by Mukari et al. (25) and Traxler (26), who studied the educational performance of hard-of-hearing children. Their findings indicated that the subjects' language performance was weaker than their math skills.

Unfortunately, there is no standardized test to assess spoken language skills in Persian language; therefore, we cannot determine the relationship between these skills and different domains of educational performance. Many 
researchers have revealed that SNHIS have major math problems. This problem seems to emerge from preschool concepts about mathematics (mainly due to impaired hearing), which may be related to later academic performance in these children (27). The impact of hearing loss on language and comprehensive reading skills has been discussed in the literature and its relation to solving math problems in deaf children has been elucidated $(4,28,29)$.

Children with hearing impairment need extra time to process sounds or speech; therefore, they miss some information which can confuse them in abstracting the meaning of conversations. Besides, hearing loss does not develop in a linear fashion. In an ideal situation, one's actual hearing should be the same as his/her hearing potential. However, hearing is a very sophisticated task, and as Smeds and Leijion (2010) stated, "There is no simple one-toone correspondence between loudness and intensity" (30). In fact, a mild change in the auditory input may interfere with actual hearing in hearing impaired students and influence their educational performance.

Additionally, in the present study, the mean ATS was $16.8 \pm 6.8 \mathrm{~dB}$ in the better ear after medical treatment, which indicates an extra mild conductive hearing loss due to otitis media. The reported ATS (or decrease in AT) improved the hearing potential in the study sample after the medical intervention. This finding is in line with a previous study by Northern and Down, which showed that even -100 $\mathrm{mm} \mathrm{H}_{2} \mathrm{O}$ elevate hearing threshold. They also revealed an approximate $27 \mathrm{~dB}$ HL shift of AT in children with bilateral otitis media (15).

The present results are also consistent with previous research, which indicated the effect of otitis media as a fluctuation of AT in subjects (aged 6 - 21 years) with bilateral sensorineural hearing loss $(9,31)$. Also, similar findings were reported by Ozturk in 2005 and Egeli in 2003, who found that otitis media is an important health problem in schools for deaf children and can influence the degree and type of hearing loss in SNHIS (9, 32).

In addition, the present findings showed that most children ( $\mathrm{n}=24,85 \%$ ) had not been visited by an otolaryngologist for more than a year, and only 4 (15\%) cases were examined within less than a year; this could imply that more children might suffer from symptomless or overlooked otitis media. This finding is in line with a study by Teel and Sade, which showed that fluctuating conductive hearing loss due to middle ear inflammation can appear, resolve, and reappear several times without any considerable signs or symptoms $(33,34)$. As a result, it is considered a risk factor for listening, communicating, and learning in hearing impaired students.

The mentioned finding is consistent with a study by Marschark in 2015, who emphasized on the analysis of so- cial and academic outcomes of hearing impaired students in order to identify the assets and risk factors at individual, family, and school levels (35). In the present study, our main interest was to show that residual hearing in SNHIS is the most valuable individual asset; in fact, features which compromise the hearing ability are considered as the most serious risk factors. Overall, lack of a regular otologic examination for SNHIS in developing countries results in failure to detect common ear diseases, while these overlooked diseases can affect the students' residual hearing or individual assets and may be associated with reduced educational performance.

The current findings were also in agreement with a study by Olusanya, which implied that the full spectrum of hearing disability and rehabilitation needs of HIC, especially in developing countries, are unlikely to be properly addressed by the WHO criteria (36). Therefore, it can be suggested that in developing countries such as Iran, rehabilitation assessment of hearing impaired students is required with a community-based approach in order to identify the risk factors and enhance their assets or potentials.

Developed countries established integrated rehabilitation services through deaf education about 200 years earlier than developing countries (37). Deaf education in Iran began in 1924 by Jabbar Asgarzadeh (Baghcheban) with 3 deaf students in Tabriz. Deaf education was authorized in 1949 after 25 years of Baghcheban's continuous effort, and finally the first school for the deaf was established in 1957 in Tehran (38).

Currently, we need to consider and investigate the academic achievement of SNHIS from a general viewpoint in educational settings to determine the pitfalls and also focus on individuals with sensorineural hearing loss to identify the overlooked aspects in educational activities (eg, inappropriate hearing aids and recurrent ear diseases). Overall, policymakers in developing countries need to consider the outcomes of such studies for decision-making regarding the development of suitable strategies. It should be noted that the circumstances are completely different for SNHIS with a high socioeconomic status in Iran.

\subsection{Conclusions}

It seems that detection and treatment of overlooked otitis media in SNHIS, as part of comprehensive health care support, can improve their AT, diminish their hearing disabilities, and ameliorate their educational difficulties; consequently, health care support is associated with better educational achievement.

\subsection{Strengths and Limitations}

The present study had several limitations. First, although health cards in Iran cover approximately all chil- 
dren in any part of the country and provide immunization and growth monitoring for children, they do not include other medical records. Since the sample of the present study had a low socioeconomic background, without a clear medical history or even regular ENT examination (also, no definite health management information system), we cannot make a clinical judgment about the effect of early childhood otitis media.

Another limitation of this study was lack of standardized assessment methods for investigating different dimensions of speech and language performance in Iran. Also, lack of a standard method for educational assessment was another limitation of this study. Therefore, we applied a pretest-posttest design to compare each case with itself and also to control the probable confounders.

Another shortcoming of the present study was with respect to hearing aids. The high cost of hearing aids in developing countries could impose some limitations during the course of the study; in fact, as mentioned before, this limitation resulted in the relatively small sample size of this study. Also, ENT examination and hearing evaluation 3 times during 3 seasons was very difficult, and only 266 out of 466 children could be evaluated 3 times in our study.

Finally, we lost $6.67 \%$ of the subjects in the followups. Overall, we were faced with some problems which developed countries have already overcome. Therefore, we could not find any similar recent studies in the literature for comparison. There were also few studies in the literature regarding the effect of middle ear treatment on the educational achievement of SNHIS. Also, as mentioned earlier, studies in developing countries have not provided any information regarding AT changes and educational performance.

On the other hand, the strength of this study was the participants' strong adherence to the study and their cooperation with regular ENT examinations and hearing evaluations, which were conducted several times over the study period.

Based on the findings, the need for future ongoing integrated public health care and welfare support for SNHIS is strongly felt in developing countries. Overlooked recurrent middle ear infections or even dysfunctions are regarded as important factors, which affect the educational achievement of SNHIS. It is also necessary to perform longterm studies with a large sample size in order to confirm the findings.

\section{Acknowledgments}

We would like to thank Mrs. Malihe Sahami, the head manager of Molavi rehabilitation center, and Mrs. Maryam
Panahi, the head of the audiology department, who performed the hearing evaluations. We would also like to extend our gratitude to Ms. Horie Hasan, MSc student at the audiology department for her helpful guidance on audiology book reviews. We also thank Mrs. Samaneh Hosseinzadeh, PhD in biostatistics, and Dr. Mohsen Shati and Dr. Mehdi Noroozi, epidemiologists, for their sincere support in data analysis and interpretation. Finally, we would like to thank the hearing impaired children and their families for their cooperation.

\section{Footnote}

Funding/Support: This study was supported by the deputy of research and technology, University of Social Welfare and Rehabilitation Sciences, Tehran, Iran (grant No: 801/T/1/3468).

\section{References}

1. Yamamah G, Mabrouk A, Ghorab E, Ahmady M, Abdulsalam H. Middle ear and hearing disorders of schoolchildren aged 7-10 years in South Sinai, Egypt. East Mediterr Health J. 2012;18(3):255-60. [PubMed: 22574480].

2. Tucci D, Merson MH, Wilson BS. A summary of the literature on global hearing impairment: current status and priorities for action. Otol Neurotol. 2010;31(1):31-41. [PubMed: 20050266].

3. World Health Organization . International classification of functioning, disability and health: ICF. WHO; 2001.

4. Serrano Pau C. The deaf child and solving problems of arithmetic. The importance of comprehensive reading. Am Ann Deaf. 1995;140(3):28790. [PubMed: 8651070].

5. Islami Z, Baradaranfar MH, Mehrparvar AH, Mollasadeghi A, Mostaghaci M, Naghshineh E. Frequency of Hearing Impairment among Full-term Newborns in Yazd, Iran. Iran JPediatr. 2013;23(3):34952. [PubMed: 23795261].

6. Elbasan B, Duzgun I, Oskay D. Is There any Difference in Health Related Quality of Life, Self Care and Social Function in Children with Different Disabilities Living in Turkey?. Iran J Pediatr. 2013;23(3):281-8. [PubMed: 23795250].

7. American Academy of Pediatrics JCOIH. Year 2007 position statement: Principles and guidelines for early hearing detection and intervention programs. Pediatrics. 2007;120(4):898-921. doi: 10.1542/peds.2007-2333. [PubMed: 17908777].

8. Albertini JA, Kelly RR, Matchett MK. Personal factors that influence deaf college students' academic success. J Deaf Stud Deaf Educ. 2012;17(1):85-101. doi: 10.1093/deafed/enr016. [PubMed: 21558157].

9. Egeli E, Cicekci G, Ozturk O. Ear examination findings at the Yeditepe School for the Deaf. Int J Pediatr Otorhinolaryngol. 2003;67(8):905-10. [PubMed: 12880671].

10. Bluestone CD, Klein JO. Otitis media in infants and children. PMPHUSA; 2007.

11. The International Study of Asthma and Allergies in Childhood (ISAAC) Steering Committee . Worldwide variation in prevalence of symptoms of asthma, allergic rhinoconjunctivitis, and atopic eczema: ISAAC. Lancet. 1998;351(9111):1225-32. [PubMed: 9643741].

12. Schernhammer ES, Vutuc C, Waldhor T, Haidinger G. Time trends of the prevalence of asthma and allergic disease in Austrian children. Pediatr Allergy Immunol. 2008;19(2):125-31. doi: 10.1111/j.13993038.2007.00597.x. [PubMed: 18086231]. 
13. Quaranta N, Iannuzzi L, Gelardi M. Does the type of rhinitis influence development of otitis media with effusion in children?. Curr Allergy Asthma Rep. 2014;14(11):472. doi: 10.1007/s11882-014-0472-2. [PubMed: 25183363].

14. Baldwin RL. Effects of otitis media on child development. Am J Otol. 1993;14(6):601-4. [PubMed: 7507647].

15. Northern JL, Downs MP. Hearing in children. Lippincott Williams \& Wilkins; 2002.

16. Shapiro LR, Hurry J, Masterson J, Wydell TN, Doctor E. Classroom implications of recent research into literacy development: from predictors to assessment. Dyslexia. 2009;15(1):1-22. doi: 10.1002/dys.380. [PubMed: 19097039].

17. Elango S, Htun YN, Raza H. Additional conductive hearing loss in children from a school for the deaf in Malaysia. Int J Pediatr Otorhinolaryngol. 1994;28(2-3):125-8. [PubMed: 8157410].

18. Medu . Hearing loss 2014. Available from: www.Seo.medu.ir.

19. Bess FH, Dodd-Murphy J, Parker RA. Children with minimal sensorineural hearing loss: prevalence, educational performance, and functional status. Ear Hear. 1998;19(5):339-54. [PubMed: 9796643].

20. Khairi Md Daud M, Noor RM, Rahman NA, Sidek DS, Mohamad A. The effect of mild hearing loss on academic performance in primary school children. Int J Pediatr Otorhinolaryngol. 2010;74(1):67-70. doi: 10.1016/j.ijporl.2009.10.013. [PubMed: 19913305].

21. Zinkus PW, Gottlieb MI, Schapiro M. Developmental and psychoeducational sequelae of chronic otitis media. Am J Dis Child. 1978;132(11):1100-4. [PubMed: 82400].

22. Reichman J, Healey WC. Learning disabilities and conductive hearing loss involving otitis media. J Learn Disabil. 1983;16(5):272-8. [PubMed: 6348190].

23. Lim SY, Simser J. Auditory-verbal therapy for children with hearing impairment. Ann Acad Med Singapore. 2005;34(4):307-12. [PubMed: 15937571].

24. Antia SD, Jones PB, Reed S, Kreimeyer KH. Academic status and progress of deaf and hard-of-hearing students in general education classrooms. J Deaf Stud Deaf Educ. 2009;14(3):293-311. doi: 10.1093/deafed/enp009. [PubMed: 19502625].

25. Mukari SZ, Ling LN, Ghani HA. Educational performance of pediatric cochlear implant recipients in mainstream classes. Int J Pediatr Otorhinolaryngol. 2007;71(2):231-40. doi: 10.1016/j.ijporl.2006.10.005.
[PubMed: 17109974].

26. Traxler CB. The Stanford Achievement Test, 9th Edition: National Norming and Performance Standards for Deaf and Hard-of Hearing Students. J Deaf Stud Deaf Educ. 2000;5(4):337-48. doi: 10.1093/deafed/5.4.337. [PubMed: 15454499].

27. Pagliaro CM, Kritzer KL. The Math Gap: a description of the mathematics performance of preschool-aged deaf/hard-of-hearing children. Deaf Stud Deaf Educ. 2013;18(2):139-60. doi: 10.1093/deafed/ens070. [PubMed: 23307889].

28. Hyde M, Zevenbergen R, Power D. Deaf and hard of hearing students' performance on arithmetic word problems. Am Ann Deaf. 2003;148(1):56-64. [PubMed: 12765091].

29. Kelly RR, Lang HG, Pagliaro CM. Mathematics word problem solving for deaf students: a survey of practices in grades 6-12. J Deaf Stud Deaf Educ. 2003;8(2):104-19. doi: 10.1093/deafed/eng007. [PubMed: 15448061].

30. Smeds K, Leijon A. Loudness. Springer; 2011. pp. 223-59.Loudness and hearing loss.

31. Stool SE, Craig HB, Laird MA. Screening for middle ear disease in a school for the deaf. Ann Otol Rhinol Laryngol Suppl. 1980;89(3 Pt 2):1727. [PubMed: 6778301].

32. Ozturk O, Silan F, Oghan F, Egeli E, Belli S, Tokmak A, et al. Evaluation of deaf children in a large series in Turkey. Int J Pediatr Otorhinolaryngol. 2005;69(3):367-73. doi:10.1016/j.ijporl.2004.11.001. [PubMed: 15733596].

33. Teele DW, Klein JO, Rosner BA. Epidemiology of otitis media in children. Ann Otol Rhinol Laryngol Suppl. 1980;89(3 Pt 2):5-6. [PubMed: 6778349].

34. Sade J. Pathology and pathogenesis of serous otitis media. Arch Otolaryngol. 1966;84(3):297-305. [PubMed: 5946810].

35. Marschark M. Educating Deaf Learners: Creating a Global Evidence Base. Oxford University Press; 2015.

36. Olusanya BO, Newton VE. Global burden of childhood hearing impairment and disease control priorities for developing countries. Lancet. 2007;369(9569):1314-7. doi: 10.1016/S0140-6736(07)60602-3. [PubMed: 17434407].

37. Hull RH. Aural rehabilitation. Citeseer; 1992.

38. Ebrahimi A. Hearing Journal of exceptional education; 2007. Available from: http://magiran.com. 